be infected by water contaminated by bone dust, but I have not heard or read of any case in which man has been infected by bone dust directly.

2. The rapid course of the disease.-The patient first complained of the itching on May 5th and he died on the 9thi.e., four days after the onset of the disease. This is about the earliest period at which death may occur, although several cases have been reported in which death took place on the third day. As a rule, however, the disease lasts longer than four days.

3. The temperature.-The patient's temperature did not rise above $100^{\circ} \mathrm{F}$. Some say that the temperature in malignant pustule does not rise at all. Greenfield ${ }^{3}$ says : "This may be true in some cases in which there is no general infection. In other cases, while the surface temperature may be subnormal, the rectal temperature is elevated." Other authorities say that in cases of malignant pustule the temperature never rises above $102^{\circ}$.

4. The site of the lesion. - In this case the site of the lesion was unusual, for in no case which I have come across bas the lesion been situated on the breast. The commonest sites are the face, neck, arms, and hands. In this particular case, as mentioned above, I learned that the patient had been in the habit of scratching his breast and it seems very probable that his hands had conveyed the infection.

5. The absence of pain and severe constitutional symptoms.The absence of pain is of interest as distinguishing malignant pustule from phlegmonous erysipelas, a disease in which there is severe pain and with which malignant pustule is often confounded. As regards the absence of severe constitutional symptoms Greenfield ${ }^{4}$ says that "even in cases which prove fatal there may be few or no general symptoms at first and the patient may even continue at work with a large distinct pustule, or there may be only a slight degree of prostration with a little fever."

6. The absence of feeling of distress.-The absence of feeling of distress or anxiety on the part of the patient and his clear mental condition are also interesting features to which many writers refer.

The treatment which I adopted from the beginning was strong carbolic dressings locally and tonics. The majority of surgeons advise excision of the pustule, although it is said there is great danger in the operation in allowing the entrance of the bacilli into the blood stream. Others advise the injection of carbolic acid subcutaneously around the seat of inoculation.

Friockheim, N.B.

\section{ON THE LIMITS OF THE HEART DULNESS IN CASES OF AN EMIA AND CHLOROSIS.}

By R. WYBAUW, M.D.,

DOCTEUR SPÉCLAL OF THE BRUSSELS UNIVERSITY; ASSISTANT PHYSICIAN TO ST. JOHY'S HOSPITAL, BRUSSELS.

DURING recent years the diagnosis of valvular disease of the heart has undergone a remarkable change. 20 years ago the principal object of the physician was to recognise exactly the seat and the nature of the supposed valvular trouble, and to give a precise anatomical name to it. Nowadays this is no longer sufficient, and much more attention is paid to the state of nutrition and to the function of the heart muscle itself, its strength, and its ability to overcome the increased resistance of the blood.

Normally the wall of the heart, and especially that of the yentricle, has sufficient strength to expel the blood from its cavities into the arterial system, even when the bloodpressure is slightly increased. Of course, if the muscle loses its strength because its nutrition is impaired a com plete contraction will be impossible and dilatation will occur. German and Swedish observers have studied minutely the mechanism of "dilatation from overstrain" (Ueberanstrengungs-dilatation) in cases of valvular diseases, of general affections, of anæmia, \&c. It is produced when the relation between the blood-pressure in the heart cavity (and more particularly in the ventricle) and the strength of the muscle is no longer normal, the latter being unequal to the former. This may occur in two ways: (1) the bloodpressure may be abnormally increased; and (2) the muscle may be abnormally weak and its contraetion less effective.
Many infectious diseases cause a similar weakness of the heart, accompanied by dilatation; it exists in a more chronic character in many kinds of valvular diseases or of infection (diphtheria, scarlet fever, typhoid fever, \&c.), when the nutrition of the muscle cells is impaired because the blood of the coronary system is more venous or less oxidised, or because its chemical constitution is abnormal. In anæmia and in chlorosis the same conditions exist. In them an acute dilatation of the heart has been frequently observed, with or without recovery and return to the normal size of the heart when the disease had passed away. Recovery is, however, not always possible, for it seems probable that a certain amount of hypertrophy may be added to the primary dilatation.

What happens in chlorosis? The cause of the disease is still unknown-it may be a nervous, trophic, or chemical influence; it is certain, however, that many muscle cells, and especially unstriped muscle cells, lose their tonus and consequently the cavities in the wall of which they are contained have a well-marked tendency to dilate. Dilatation of the stomach and dilatation of the intestine are very frequently found. Professor Glax of Abbazia thinks that in chlorosis there is a general infiltration of the tissues by effused bloodserum-indeed, when the condition of the patient begins to improve the quantity of urine increases and the weight diminishes. Even here where the pure air, the walks, \&c. cause an increase of weight in normal individuals after a few days passed in Spa, I often saw the weight of anæmic girls diminish whilst the symptoms markedly improved. It is possible that a similar infiltration as supposed by Professor Glax may exist in the heart tissue and cause a diminishing of force leading to dilatation of the organ as well as in the intestine or stomach. Of course no reference is here made to the common symptoms of heart murmurs in anæmia and chlorosis, only the functional strength of the muscle is at present under consideration. It is well known that a marked murmur may be produced by very little change in the heart's condition (accidental murmurs), or the contrary may be found in many cases. The trouble of the heart function itself is only to be detected by percussion, by examining the pulse, or by the use of radiography (Grüomach)

As it is very difficult for practitioners in bath resorts to obtain a complete history of patients, I here give the history of a young girl whom I saw in Professor Destrée's wards in the Brussels Hospital. She was 16 years of age and entered the hospital on March 25th, 1899. Her father died from tubercle. She had felt herself quite well until five days before her admission, when she suddenly suffered from severe pain in the right hypochondrium and the epigastrium. On examination no other trouble was detected than great anæmia with loss of hæmoglobin and a well-marked increase of the heart dulness, relative and absolute. The relative dulness extended upwards to the second rib and downwards to the lower border of the sixth rib. It extended three centimetres (one and a quarter inches) to the right and 10 centimetres (four inches) to the left from the medio-sternal line. Absolute rest was prescribed and the pain disappeared after three days. The patient soon left the hospital, saying that she felt quite well, the area of the heart dulness being little changed. Immediately after leaving she continued her ordinary hard work and was obliged to re-enter the hospital on July 27th. She only complained of pain in the epigastrium and in the left side. Her general state of health was worse. The stomach was neither displaced nor dilated, but the heart extended $11 \frac{1}{2}$ centimetres towards the left, and four and a half centimetres to the right. The apex beat was to be felt in the sixth intercostal space. The patient remained three weeks in the bospital. The limits of the heart dulness changed a little (11 centimetres at the left and three centimetres at the right side of the mediosternal line). There was no tubercle.

In this case the extent of the dulness outwards and downwards without the slightest sign of heart disease, and its rapid increase during the hard work from the end of April to the end of July, clearly indicated the existence of an uncomplicated dilatation of the heart. This question is a very important one, for several German writers, including von Noorden, Müller, and others, think that in chlorosis there is no dilatation but only a displacement of the heart. The dulness would only seem enlarged because the diaphrs gm in those patients is higher than normal and causes the heart to be pushed upwards, its greater diameter becoming more horizontal and its right border being displaced towards the right, and the apex outwards but not downwards. Grünmach 
published in the Therapentisone Monatshefte the result of radiugraphic examinations and demonstrated the displacement of the diaphragm in cases of chlorosis and other similar diseases. Such cases, no doubt, exist, but in medical science it is desirable to avoid generalising too hastily. I had recently an opportunity of observing several cases in which the apex beat was really displaced outwards but not downwards ; it was even found to be in the fourth intercostal space. I think that in those cases there is no dilatation at all, but $I$ find it imprudent to deny completely the possibility of dilatation in chlorosis. Botb are possible, and it may be said that in many cases of chlorosis and anæmia there exists a dilatation of the beart cavities causing an increase in the size of the heart dulness, the apez beat being di.placed outwards and downwards. On the other hand, dilatation may be only simulated by a displacement of the diapuragm causing the great diameter of the heart to be more horiz ontal and the apex-beat to be displaced outwards and downwards.

I saw once a very tall youth, aged 16 years, who was in a very bad condition of health which was caused by improper hygienic conditions. He suffered from pain in the epigastrium, and examination revealed only an enlargement of the left ventricle. After several days of absolute rest this dilatation ceased and the limits of the heart became normal. There was no murmur to be heard, but there was cyclic albuminuria which appeared every afternoon. The patient left the hospital after a week's treatment, and soon afterwards (in five weeks) came back wich his heart considerably enlarged. Rest and appropriate diet sufficed to restore him a second time, but the cyclic albuminuria remained. Such cases occucring amongst young men may also be considered as a frequent cause of heart dilatation. The muscular wall of the ventricle being in a bad state of nutrition, the blood is incapable of nourishing the muscle cells.

With regard to the treatment in cases of anæmia the greatest importance should be attached to the functional state of the heart. In many cases, especially in commencing chlorosis, walking and other forms of exercise are recommended and often with a good result, but in more advanced cases absolute rest is necessary in order to strengthen the heart and to prevent oppression, \&c. It is interesting to notice that in general the patients complain not only of heart palpitation but of pain in the epigastrium. Many of them, having a well-marked heart dilatation, do not notice any abnormal feeling in the præcordial area, and the epigastric pain often disappears when the dulness regains its normal size.

In a bathing-place like Spa, where hydropathic treatment is almost always combined with the internal use of the ferruginous waters, the examination of the heart must never be omitted; indeed, stimulating the circulation and torpid nervous system will greatly help the internal action of the absorbed iron. That combined action, indeed, gives the best result. In cases, however, where the heart is enlarged and the oppression is intense and in some other cases the use of douches may be dangerous, the patient not being able to stand the sudden shock of the water. In such cases baths of natural carbonic acid water are generally found very useful.

Baths of carbonic acid water may be given in cases of chlorosis and anæmia with increase in the area of cardiac dul. ness. (Palpitation may be nervous and is not a criterion as to the condition of the heart; pure nervous palpitation is often improved by hydropathic treatment with cold water.) As already mentioned the heart becomes enlarged because the blood-pressure is too strong for its feeble muscle. The carbonic acid bath causes a gentle but general action on all parts of the skin. Soon after entering it the patient feels the bubbles of carbonic acid on every part of his body and the skin becomes red, the peripheral vessels are dilated, and the pulse becomes markedly slower and increases in strength. All cutaneous blood-vessels dilate, thereby diminishing the work of the heart. It is, of course, in the rame manner that the baths of Nauheim ro greatly improve many cases of heart disease-namely, by diminishing the pressure in the vascular system. Indeer, carbonic acid baths, associated with the internal use of chalybeate water, give the best results in the treatment of anæmia with heart weakness. It is necessary to ascertain the extent of the heart-dulness accurately in order to determine whether exercise or rest is required in the treatment or whether douches or baths will be the more efficacions.
Potain and Vaquez: Semaine Médicale, 1895, p. 415. Von Noorden : Die Bleichsucht, Notbnagel's Specielle Pathologie und Therapie, Band viii., 1. Griinmach: Therapeutische Monatsbefte 1897, 1. Talma Nederlandsch Tijdschrift voor Geneeskunde, 1895, 10 Muiller: Berlines Klinische Wochenschrift, 1895, 38 Henschen: Fischer, Jeva, 1898 Glax : IIandbuch der Balneotherapie, Band ii., 1900. Spa, Belgium.

\section{CASE OF SUPRA-HEPATIC HYDATID CYST.}

\section{BY GEORGE W. DAVIS, M.D., B.S. DURH. L.R.C.P. LOND., M.R.C.S. ENG.}

THIS was a hydatid of about 25 ounces capacity situated between the liver and the diaphragm. The diagnosis was difficult even beyond the generality of hydatids. The patient had a healthy appearance and there was an absence of any concrete symptoms other than that of the percussion outline and skiagram.

A symptom of remarkable character was the diminished urination, almost amounting to anuria, which in association with menorrhagia and slight swelling of the legs was evidently due to pressure on the rena cava by the cyst, probably at the point of the passage of the vein through the diaphragm.

In spite of the apparent well-being of the patient her life was imperceptibly but very definitely ebbing away. She was very gradually losing strength and energy ; from being a woman who took an active part in the household management she could merely lie on her bed or sofa, walk short distances, and go about in a bath chair, and even this slight exertion was accomplished with increasing difficulty.

The case was sten by Sir William Broadbent, Bart., by Mr. Charters Symonds, by Mr. Golding-Bird, by Mr. G. H. Makins, by Mr. F. G. Larkin, and by Dr. Barry Blacker. She was first seen by. me on Nov. 12th, 1888 The operations were performed on April 12th and 16th, 1899, by Mr. G. H. Makins and the convalescent period extended over two and a half months, during the whole of which time there was much danger of septic infection from the character of the walls of the cyst which kept it gaping and in continual movement.

The patient was a multipara, aged 36 years, and had four healthy children between the ages of seren and 16 years. Her father died from enlargement of the liver at 60 years of age, her mother died from "cancer" at 60 years of age, and an aunt is suffering from multiple abdominal tumours the character of which have not been diagnosed. She has eight brothers and two sisters alive and bealthy. Except for confinements and three miscarriages the patient had never ailed until 1894 when Mr. F. G. Larkin discovered the abdominal hydatid which was removed by operation in two stages by Mr. Charters Symonds.

On Nov. 12th, 1898, I was first consulted on account of blood passed by the bowel, apparently due to some obstruc. tion of the vena portæ. This led to a careful examination of the liver, but it will be easier to grasp the main facts of the ca:e by reviewing the chief symptoms separately during the period of five months preceding the operation, then describing the operation, and afterwards the convalescence.

The patien was fair-complexioned, fresh in colour, very young looking, and had such an appearance of absolute health that it was extremely difficult to impress upon the minds of those who saw her for the first time that actually she was seriously ill - as a matter of fact, fading gradually both as to weight and strength. Her weight in November, 1898 , was 8 st. $12 \mathrm{lb}$., and in April, 1899, it was but 8 st. The difficulties of obtaining recognition of the gravity of her condition were further increased by the fact of her occasional improvement in health. Thus at one time she regained $4 \mathrm{lb}$.

The entire right chest was ratber more prominent than the left chest, the measurements being $15 \frac{1}{8}$ inches on the right side and $14 \frac{1}{4}$ inches on the left. The dulness of the liver by percussion-the arms being extended by the side of the head-was seven inches vertically in the middle line, five inches on the right side of the enciform cartilage, and five inches in the posterior axillary line. The dulness could not be defined posteriorly. I found that I could percuss ont the liver much more correctly when standing to the left of the patient (Fig. 1).

The dome-like character of the cyst made it difficult to define by percussion and in liebruary I had a skiagram taken 